\title{
Determinants of effective high-risk cargo logistics at sea ports: A case study
}

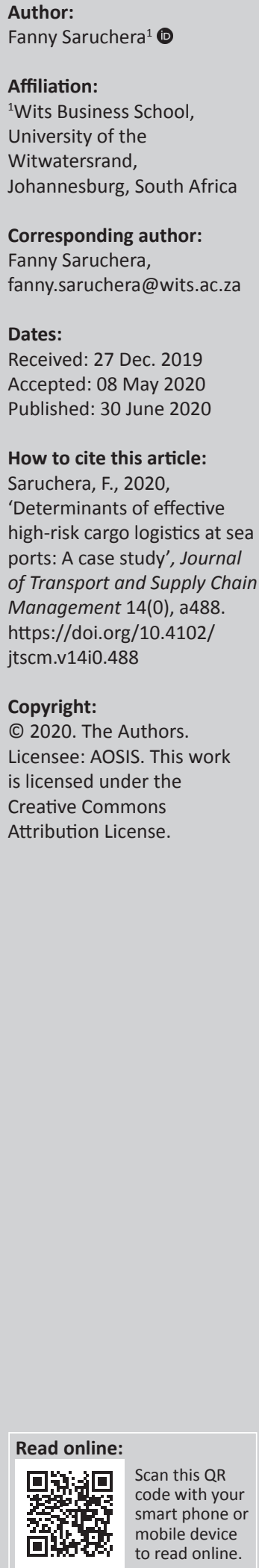

Background: In recent decades, accidents involving hazardous goods at seaports have become a major concern worldwide resulting in international conventions and interventions to minimise the impact of such accidents. Despite the improvements in safety measures and the enhancement of cargo handlers' knowledge over the years, port accidents involving dangerous substances still continue to occur.

Objectives: The study explores the determinants of effective high-risk cargo (HRC) handling at seaports, focusing on Namibian seaports. The study was aimed at establishing the elements of HRC logistics processes and to determine factors influencing the effectiveness of HRC handling procedures followed by the seaports.

Method: An integrated research strategy was adopted, backed by the employment of mixed research methods, through seven key informant interviews and a quantitative survey involving 81 port employees.

Results: The results of the study confirmed the totality of HRC logistics activities at Namibian seaports. It emerged from the study that there were factors that facilitated and that hindered the effectiveness of HRC logistics activities at Namibian seaports. The study confirmed the association between HRC training and the level of knowledge of risk mitigation and emergency procedures, documentation understanding and regulations adherence. This guided in proposing a new theory for the determinants of HRC logistics in developing economies.

Conclusion: The study's findings provided sufficient evidence to suggest that HRC logistics safety processes at seaports can be improved through the proposed framework. The study's findings have important repercussions for re-shaping public policy, especially as coastal economies worldwide compete towards becoming preferred logistics hubs.

Keywords: dangerous goods; effective logistics; high-risk cargo; seaports; port risk management; port safety.

\section{Introduction}

The increasing role of seaports in global logistics and supply chain management cannot be overlooked. However, over the last decade, ports have been marred with both man-made and natural disruptive events such as port accidents, extreme weather disruptions, earthquakes and spillages involving dangerous (high-risk) cargo. The impact of such disruptive events has been felt across the supply chain, down through to the end consumers and society at large (Lam \& Lassa 2017; Loh \& Thai 2015). This has resulted in increased research focusing on port safety and risk assessment and/or management (Fabiano et al. 2010; Liu, Zhou \& Sun 2019; Pak et al. 2015; Yang 2011; Yang et al. 2016). In pursuance of such port safety research interests, this study focused on establishing the determinants of effective dangerous cargo (DC) logistics, focusing on Namibian seaports. More specifically, the study was aimed at establishing the elements of high-risk cargo (HRC) logistics processes followed by Namibian seaports and to determine factors influencing the effectiveness of the HRC handling procedures used by the ports.

Operated by the Namibian Port Authorities (Namport), Namibian seaports serve as a gateway for entry of goods destined for Namibia as well as for most landlocked Southern African countries, such as Botswana, Zambia and Zimbabwe (Namport 2019a). According to Namport's 2016-2018 annual reports, Namport handles over 5.5 million tonnes of cargo annually (Namport 2018). About $47 \%$ of this cargo is classified as HRC or DC by the International Maritime Dangerous Goods (IMDG) code (International Maritime Organization [IMO] 2018). The Walvis Bay Port has been expanding its infrastructure since the beginning of 2015 and the 
first phase of the expansion was completed in August 2019 (Namport 2019b). It is thus anticipated that larger volumes of cargo will be handled through the port, much like several other ports in the world. These figures are set to grow in view of the current expansion of the port, as it is set to grow into the 'gateway' to Southern Africa (De Klerk 2013; Finck 2017; Saruchera 2017; Savage et al. 2014). Port safety concerns may thus not be ruled out, as the increase in cargo handled at the port would also imply a likely increase in HRC.

Despite the development of, and improvements in, safety measures over the years, port accidents involving dangerous substances continue to occur (He, Zhang \& Mol 2011). Namibian seaports have not been immune to such port accidents. There have been reports of accidents involving dangerous substances during the loading and offloading, storage and transportation into, out of and within the port areas. For instance, there have been incidents in the form of sporadic fires, toxic releases, corrosiveness, and the more recent unexplained oil spillage (de Klerk 2018). These incidents have had an impact on the surrounding environment, financial losses, damage to other cargo and port infrastructure (Batarliene 2018; de Klerk 2018), with the possible conception of negative perceptions by the port stakeholders.

Handling of huge amounts of DC provokes accidental events, not only in ports but during transportation from both within and without the port area (Batarliene 2018). It is evident that the Namport handles lots of DC, and it is necessary to probe whether current DC handling procedures have resulted in any challenges that may have caused danger. This study was thus aimed at exploring the determinants of effective DC logistics at Namibian seaports. More specifically, the objectives of the study were: to establish the elements of HRC logistics processes followed by Namibian seaports; and to determine factors influencing the effectiveness of HRC handling procedures used by Namibian seaports with a view to establish an integrated business model to improve HRC logistics at Namibian seaports.

\section{Literature review and conceptual framework}

High-risk cargo is loosely referred to as 'dangerous cargo (DC)', 'hazardous materials (hazmat)' or 'dangerous goods (DGs)' in maritime logistics literature. Although these terms may be used interchangeably (Ots 2000), the best way to distinguish the terms is through highlighting the three functional areas in which dangerous substances are involved - production, logistics and transportation, and consumption (Mah 2015; McCurry 2014). Dangerous Cargo can be classified into packaged and bulky DC (Mullai 2006). The IMO documents make use of both 'dangerous goods' and 'dangerous cargoes' (IMO 2018).
According to the United Nations (UN) classification, there are more than 3000 items listed as DGs in the IMDG Code. If mishandled, DGs may result in accidents through toxic releases and explosions, hence impacting the environment (He et al. 2011). Since high risks are involved in handling DC, McCurry (2014) calls for the need for total involvement of all the supply chain players to ensure safety. There seems to be, however, a portion of the maritime logistics community that is still unaware of their responsibilities in the logistics activities of DC and this has, over the years, served as one of the barriers to maritime logistics industry integration (Yuen \& Thai 2017).

\section{Elements of high-risk cargo logistics procedures}

McCurry (2014), proffers that DC logistics starts from the point when the goods are prepared for shipping, and then continues through the actual shipping right through to the destination port. The offloading, transhipment, unpacking and repacking, transportation and storage of the cargo within the seaport area also constitute DC logistics activities (Batarlienè 2018; Mangan, Lalwani \& Fynes 2008). For the purposes of this study, the delineation of DC logistics shall be limited to the handling of the HRC within the seaport area, that is, offloading, in-port transportation, packaging and repackaging, and storage activities.

\section{Loading and offloading high-risk cargo}

The UN regulations (2011) require that DC be authorised by a competent authority before loading and offloading of the cargo. This helps in ensuring that all safety requirements stay observed in order to avoid accidents. The regulations stipulate all forms of preparations that should be put in place prior to loading and offloading DC. These include temperature compliance, freeing the area of any harmful objects and maintaining the pressure of containerised goods. The regulations further require that only competent and authorised personnel must load and offload DC. The loader is expected to comply with specific requirements concerning compatibility and segregation depending on the class of the DC being loaded or off-loaded. The regulations further require the loader to hand over the DC to the carrier only if they are authorised to transport such cargo (UN 2011). The regulations have been supported by scientific literature. For instance, Martins et al. (2016) emphasised the need for strict construction rules when constructing DC loading infrastructure, DC control systems and the use of 'specialised and trained $\mathrm{crew}^{\prime}$. Sukmanee, Kesvarakul and Janthong (2019) reiterate the need for risk prioritisation and the significance of following a sequential approach to loading and offloading DC.

\section{High-risk cargo in-port transportation}

Mangan et al. (2008) define in-port transportation as the movement of cargo from one point to another within the port area. This can involve transportation from the vessel to the storage point, or vice-versa. It also includes transportation 
within the port waters (Loh \& Thai 2015). The incorrect handling of HRC during in-port transportation may result in collisions within the port waters (Loh \& Thai 2015), and accidents within the port area (He et al. 2011), resulting in water pollution and spillages on the ground surface. This will ultimately result in the destruction of the port environment.

\section{Packaging and repackaging}

Packaging helps in protecting the product before consuming it. Because of the many handling operations during long supply chains, many products require stability and protection (Ellis 2011). Packaging and repackaging are becoming increasingly important because of the escalating integration of seaports into supply chains and that has resulted in the need for the provision of such value-added services (Loh \& Thai 2015). At the same time, all these handling operations need time, and packages help to aggregate small freight units to reduce the quantity of handling operations and, afterwards, to reduce the ultimate cost for the customers. With regards to packaging and repackaging HRC, special instructions should be followed (Ellis 2011). Improper packaging, incorrect labelling and container stuffing have been considered to be some of the key contributors to DC releases on-board.

\section{Segregation and securement}

The UN Regulations have classified DC into nine classes in accordance with the type or nature of hazard involved in the cargo (IMO 2018; UN 2011). The UN regulations on DGs call for proper segregation of such goods according to the descriptions given for each of the nine classes. In 1974, the IMO spearheaded the ratification of the International Convention for the Safety of Life at Sea (SOLAS), a convention that is internationally recognised in regulating the handling and transportation of DC (Liu et al. 2019; Zekos 2000). The IMDG code (IMO 2018) provides for a detailed explanation of how specific types of goods, packages or containers should be segregated. The code, which is amended every two years (IMO 2018), also provides for the appropriate codes, symbols and terms used in the securement and segregation of HRC. These must be followed strictly to avoid and/or minimise avoidable hazards.

\section{High-risk cargo storage and stowage}

Even though the terms 'storage' and 'stowage' have generally been confused, their meaning and usage in maritime logistics is quite distinctive. Whilst storage relates to the safe-keeping of goods, usually in a warehouse or any other designated storage place (Wilson, Roach \& Ware 2001), stowage is mostly used to refer to storage or securement of goods in a vessel for transportation purposes (Batarliené 2018; Ding \& Chou 2015). The IMDG code provides guidelines which must be followed for the stowage of HRC, materials or substances, both from within and from out of the port area (IMO 2018). The code also outlines the stowage categories for the different DGs classes, thus providing for the need for segregation as explained earlier.

\section{Documentation, labelling and marking}

It is not enough to simply have the appropriate package and to follow the correct packaging or repackaging procedures. There is need for appropriate marking, labelling and documentation of the cargo, and this is particularly significant in the case of HRC. All parties involved in the handling and transportation chain of goods must know the nature of the goods with which they are dealing (Ots 2000). According to the IMDG Code (2016 edn.) (IMO 2018), there is also a need to place appropriate placards marked with the correct international UN numbers allocated for different cargo from different DGs classes. The IMDG code calls for appropriate documentation, labelling and marking, as this helps, especially in cases of emergency where the response crew may have to take certain precautionary measures in responding to the emergency.

\section{Factors influencing effectiveness of high-risk cargo logistics}

Accidents involving HRC have serious implications that are capable of bringing the entire supply chain to a standstill (Loh \& Thai 2015). Thus, the best way to avoid such serious repercussions is to ensure effectiveness in the management of HRC at seaports. This study borrows the long-established views of Darbra and Casal (2004), supported by Loh and Thai (2015), who define effectiveness in seaport risk management as a disruption-free environment. Such effectiveness is, however, influenced by several factors.

Literature seems to have remote and fragmented views regarding the factors influencing the effectiveness of HRC logistics, especially in port areas. For instance, Alderton and Saieva (2013) emphasise the need for proper identification of hazardous cargo once they enter the port area. Darbra and Casal (2004) focus on the need for appropriate technical equipment and infrastructure, whilst Gusik, Klumpp and Westphal (2012) emphasise the importance of training of personnel responsible for handling HRC. In support of Mullai (2006), Frémont (2008) puts much emphasis on the need for strict adherence to both national and international legislation.

\section{Port equipment and infrastructure}

Over the years, seaports have come to be understood as 'logistics centres' that integrate inland and maritime transport with the industrial, commercial, regional and the logistics and distribution functions (Montwiłł 2014). In order to fulfil these functions, there are several activities, processes and/or terminal facilities that take place within the port area, and each of these requires some appropriate infrastructure attributes if the desired economic benefits are to be fully obtained from the seaport (Tsinker 2014). For instance, it is common knowledge that containerisation has radically changed the infrastructural requirements of seaports (Rodrigue, Comtois \& Slack 2016). With containerisation also come bigger ships requiring improved seaport handling infrastructure. These views mostly relate to the general port 
handling equipment. Specialised equipment might therefore be required for handling DC. Although HRC is more exposed to accidents during handling and transportation (Darbra \& Casal 2004), it is essential that storage infrastructures are planned in a manner that helps to preserve port employees' lives and the safety of the cargo handled (Wallace \& Webber 2017). The use of inappropriate and/or outdated port equipment has been labelled as one of the causes of port accidents, and hence disruptions (Rodrigue et al. 2016). It is therefore critical to make use of the correct equipment to avoid disruptions at the seaports.

The current study predicts that most seaports in developing economies such as Namibia, have been found to be lacking such equipment - an issue that has to be arrested urgently if the envisaged port competitiveness is to be achieved (Zhang \& Roe 2019). The above views related to the general port handling equipment imply an even worse scenario for specialised equipment for handling DC. This study thus hypothesises that:

$\mathbf{H}_{1}$ : Effective DC handling is dependent on appropriate and adequate port equipment and infrastructure.

\section{Knowledge of risk mitigation and emergency procedures}

Almost three decades ago, Rubin (1991) established four phases of emergency management, namely, mitigation (predisaster), preparedness (pre-disaster), response (disaster), and recovery (post-disaster). These phases have different information and time requirements. Of these four phases, Berke, Kartez and Wenger (1993) argue that the recovery phase was the least understood. However, more recent studies have ruled this out by proposing procedural methodologies for disaster recovery (Smith, Martin \& Wenger 2018). Whilst there seems to be a host of studies on emergency management, it is the knowledge of such mitigation and emergency procedures that really matters in ensuring effective HRC logistics. It is also important to note that disaster management remains the responsibility of everyone within the port area and such responsibility is even extended to the surrounding communities in order to attain what Pearce (2003) terms 'sustainable hazard mitigation'.

This study supports the views of Kunz, Reiner and Gold (2014), who advocate for firms to invest in disaster management abilities. Based on the disaster response (Callaghan 2016) and chaos (Koehler, Kress \& Miller 2014) theories, the current study is of the view that such investments should focus primarily on pre-disaster phases of mitigation and preparedness. This led to the hypothesis that:

$\mathbf{H}_{2}$ : Effective DC handling depends on the level of knowledge of risk mitigation and emergency procedures.

\section{Training and development}

The preceding factor emphasised the need for knowledge of risk mitigation and emergency procedures. Such knowledge does not come on its own, hence Gusik et al. (2012) have emphasised the need for training of personnel responsible for handling HRC. With the new 'logistics centre' role of modern-day seaports (Montwiłł 2014), it is important that seaport personnel have the essential proficiencies required to achieve port efficiency (Chang \& Thai 2016). The efficiency and effectiveness of human capital contributes not only to port performance, but also to the manner in which port challenges can be tackled.

The International Labour Organisation (ILO) (2018) notes that there has been a radical shift in the skills development and requirements for ports worldwide. The organisation also notes that due to the increasing need for a skills framework for constantly-changing port job profiles, there has been a shift from job analysis to competency-based training (ILO 2018). The UN (2012) notes that the handling of HRC specifically requires personnel who have been trained to handle such cargoes. This clause is also noted by the IMDG code (IMO 2018). The current study further envisages that such training will also enhance the level of knowledge of risk mitigation and emergency procedures. Despite this requirement, this study predicts that seaports still violate these requirements in handling $\mathrm{HRC}$, hence the hypothesis:

$\mathbf{H}_{3}$ : There is a positive association between training and development and the level of knowledge of risk mitigation and emergency procedures.

\section{Proper documentation}

Effective HRC logistics is also influenced by documentation. There is a need for adequate and correct documentation (Santis \& Marcicano 2020). Slight discrepancies may prevent the shipment or transhipment of the cargo, and may result in non-payments as well as challenges with the customs officials (House 2015). The UN regulations on DGs are also quite clear regarding the need for precise documentation and labelling (UN 2011).

Appropriate documentation helps, especially in cases of emergency where the response crew may have to take certain precautionary measures in response to the emergency. For instance, the fire extinguishing material for gasoline varies significantly from the extinguishing materials and procedures for a fire caused by kerosene, even though both products fall under Class 3: Flammable liquids (IMO 2018). Precise documentation thus enhances the effective handling and transportation procedures by the succeeding players involved in the transportation chain of the merchandise (Liu et al. 2019). Whilst the focus of the current literature and regulations has been on documentation, this study focuses on an understanding of the documents, hence the hypotheses:

$\mathbf{H}_{4 a}$ : There is a positive association between training and development and the level of understanding and interpretation of HRC documentation.

$\mathbf{H}_{4 \mathrm{~b}}$ : There is a positive association between effective DC handling and the level of understanding of the documentation involved. 


\section{Regulatory environment}

In support of Mullai (2006), Frémont (2008) puts much emphasis on the need for national, regional, international and global legislature. Due to their hazardous nature, DCs are governed and regulated by international organisations such as the UN, the United Nations Conference on Trade and Development and the ILO (Santis \& Marcicano 2020; UN 2011). Mullai (2006) posits that regulatory frameworks have been formulated to control all aspects of maritime logistics, including transportation, health and safety, operational and technical factors. Dangerous goods regulations have thus been categorised based on the geographical scope, legal effects (i.e. binding and non-binding), DC activities, transport modes and carriage form (Mullai 2006; Ots 2000).

Besides the UN global regulations whose applicability is uniform globally (UN 2011), some countries have developed their national regulatory requirements for both imports and exports into and out of their territories. The expectation is that both global and national regulations be adopted when handling DC at local ports. For instance, Wang, Chen and Wu (2015) suggest that the United States implemented a federal regulation requiring their local international ports to implement what they term 'Non-Intrusive Imaging (NII)' as well as 'radiation detection' for all in-bound vessels, following the recommendations of the 9/11 Commission Act passed in 2007. However, in their cross-sectional study, Wang et al. (2015) conclude that this United States law has reportedly caused delays across many seaports in the country, thus impacting the entire transport and supply chain of the merchandise. The authors further posit that, prior to the overall effect on the supply chain, the adherence or nonadherence of the operational regulatory framework has a potential impact on the effectiveness of DC handling within the port.

In line with UN regulations on handling DC, Popek (2019) emphasised the need to train the personnel charged with handling HRC. Based on the 'logistics centre' role of global seaports (Montwiłł 2014), Thai (2016:49) recommends the need to train and develop seaport personnel handling HRC so that they can have 'the essential proficiencies required in achieving port efficiency'. In support of Wang et al. (2015), Lam and Lassa (2017) emphasise the need to train DC personnel in regulatory adherence. Based on the above literature arguments, the study hypothesises that:

$\mathbf{H}_{5}$ : Effective DC handling can be influenced positively by a supportive operational regulatory environment.

$\mathbf{H}_{6}$ : There is a positive association between training and development and the level of regulatory adherence.

\section{Human elements}

The human element is a critical factor as it interferes with all other elements of the maritime logistics (Min 2012). A study by Ots (2000) established that a considerable number of accidents in ports are caused by human errors and failures. Rothblum (2004) supports this view and has classified human error into incorrect decision-making, improper performance of tasks, and inaction. In view of these facts, Fabiano et al. (2010) rather attributed recognition of several human elements to port safety; elements such as situational awareness, proper communication and instruction interpretations, good health, effective management of work, and personal pressure (stress) issues. In addition, John et al. (2014) argued that the totality of an assessment of seaport operational risks is only complete with the inclusion of human elements - a view further expanded by Molero et al. (2017) in their 'total safety by design' contributions in increasing the safety and operability of DC terminals.

Fabiano et al's. (2010) study concluded that the container revolution has not improved safety conditions in seaports as the human factors have not been impacted by the revolution. More recently, Molero et al. (2017), in support of Pak et al. (2015), resonated the same view, adding the captain's perspective that human elements do indeed impact port safety. All these views, however, do not specify the relationship of such human elements to HRC handling environments - a gap that the current study intended to fill by predicting the relationship between human elements and effective DC handling. Based on this, the study thus hypothesises that:

$\mathbf{H}_{7}$ : There is a positive relationship between human elements and effective DC handling.

\section{Theoretical and conceptual framework}

As noted in the review above, the available literature seems to have fragmented views regarding the determinants of effective HRC logistics. To this end, disaster mitigation and management have been perceived to be cross-disciplinary functions (Weichselgartner 2001) that captivate socio-economic, organisational, political, technological, social and physical factors. This has made it difficult to have a clear-cut theory to guide this study's framework. Consequently, the study integrated the theory of planned behaviour (Ajzen 1991) and the economic impact and recovery theory (Chang \& Rose 2012), from which the human and technical determinants were drawn for the study's conceptual framework. This study presumed human determinants (knowledge, training, human elements, regulatory violations) as well as technical determinants (port infrastructure and equipment, documentation, regulatory environment) of HRC logistics management, as illustrated in Figure 1.

The evidence provided in these theories points to the need for a model of managing risks associated with the handling and logistics of DC. The lack of such a model is one of the motivating factors of this research. Grounded upon the above literature, the ensuing conceptual framework was developed, after which hypotheses were formulated and subsequently tested. This resulted in the development of an integrated business model for HRC logistics at Namibian seaports following the deductive reasoning approach of research. 
In abstracting the determinants of effective DC logistics, this study pulls upon previous studies on factors influencing the effectiveness of HRC logistics affecting the commercialisation process, and these include studies done by Alderton and Saieva (2013), Darbra and Casal (2004), Frémont (2008), Gusik et al. (2012), Mangan et al. (2008), McCurry (2014), Mullai (2006), Popek (2019), Lui et al. (2019), as well as Santis and Marcicano (2020), amongst other studies.

\section{Research methods and design}

Given the insufficiency of original research related to HRC logistics (Tanackov et al. 2018), an integrated research strategy was adopted, backed by the employment of mixed research methods, which was mainly achieved through the use of multiple data sources. Qualitative methods through seven key informant interviews were used to collect qualitative data on 'in-depth' and 'rich' descriptions (Yin 2017) regarding how Namports handle HRC. These interviews were held with HRC management personnel to validate the research problem and to get HRC operational insights of the seaports. Thereafter, the researcher established the determinants of effective HRC logistics by carrying out a quantitative survey on 81 port employees from which quantitative data were collected (using semi-structured, selfadministered questionnaires) to verify or falsify the proposed research hypotheses. Guided by Kulshreshtha (2013), a census survey method was used, whereby the entire target population was sampled. The total population of 81 employees and seven management staff was used as the sample, given the small population size.

The use of mixed methods is gradually becoming common because of its capacity to resolve complex issues and its

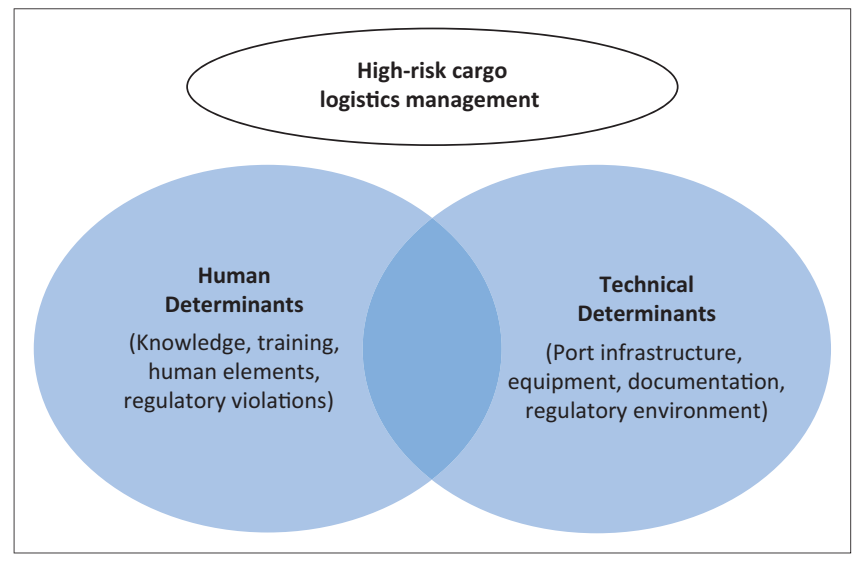

FIGURE 1: Integrated determinants of effective dangerous cargo logistics. ability to ride on the strengths of each of the methods used (Takhar \& Chitakunye 2012). Based on the benefits of this approach, it was necessary to utilise mixed research methods in order to enhance data validity and complementarity (Pinto 2010), in addition to corroboration and elaboration (Brannen 2005). Guided by Attia and Edge (2017) and Probst (2015), the researcher applied the reflexivity principles, which included self-interrogation, ethical considerations and corroboration. Table 1 summarises the justification of adopting mixed methods for the study, through the use of multiple data sources.

The questionnaires comprised both open- and closed-ended questions and this facilitated the collection of both qualitative and quantitative data. The questionnaire was sub-divided into four sections based on the themes of the study respondent demographic characteristics (Q1-Q4), factors influencing HRC logistics (Q5-Q10), HRC logistics issues and challenges (Q11-Q16), and handling and controlling HRC - confirmatory aspects (Q17-Q21). Questionnaire development was guided by the literature on HRC determinants and the conceptual framework from which various aspects such as port infrastructure, human elements and the regulatory environment constituted the relevant subsections of the questionnaire.

Quantitative data collected were analysed with the aid of the Statistical Package for Social Sciences, version 25 (IBM SPSS Statistics for Windows, version 25.0., released 2017, Armonk, NY: IBM Corp.). Both descriptive and inferential statistical analyses were used in this research. Proposed hypotheses from the conceptual framework were tested statistically. Qualitative data collected through interviews were sorted into related categories and subsets based on specified themes, coded, grouped and analysed in terms of relatedness.

\section{Ethical consideration}

This article followed all ethical standards for research without direct contact with human or animal subjects.

\section{Results and discussion}

Seventy-eight (78) of the respondents returned the questionnaire, thus there was a response rate of $96.3 \%$. All intended seven key informant interviews were held. Cronbach's alpha tests were run on each of the port employees' questionnaire's sub-constructs. Results showed that the questionnaire was highly reliable, with an overall $\alpha$ of 0.927. According to Yin (2017), triangulation has been considered to be one of such methods associated with the

TABLE 1: Justification for using multiple data collection methods for the study. 
enrichment of data validity. For this reason, this study triangulated the research methods to reduce bias and institute valid propositions. In order to reduce the potential of biased interviewing, whilst improving quality and rigour, all interviewees were asked a standardised set of questions and objectivity was ensured by probing for more information, as guided by Cypress (2017).

\section{Elements of high-risk cargo logistics processes}

One objective of the study was to establish the elements of HRC logistics processes followed by the seaports. It is evident from Figure 3 below that respondents indicated that all of the eight HRC processes proposed in the questionnaire were followed by the Namibian seaports. All of the respondents alluded to the fact that their ports engaged in, and they had been exposed to, loading and offloading, packaging and repackaging, storage and stowage, as well as documentation. Whilst $20 \%$ of the respondents indicated that they had been exposed to other processes that were not mentioned in the questionnaire, and these included breaking bulk, transshipment and liaison with national bodies regarding the importation or exportation of certain hazardous materials. The researcher, however, assumed that these 'other processes' had already been included in the categories of packaging and repackaging, in-port transportation, and documentation.

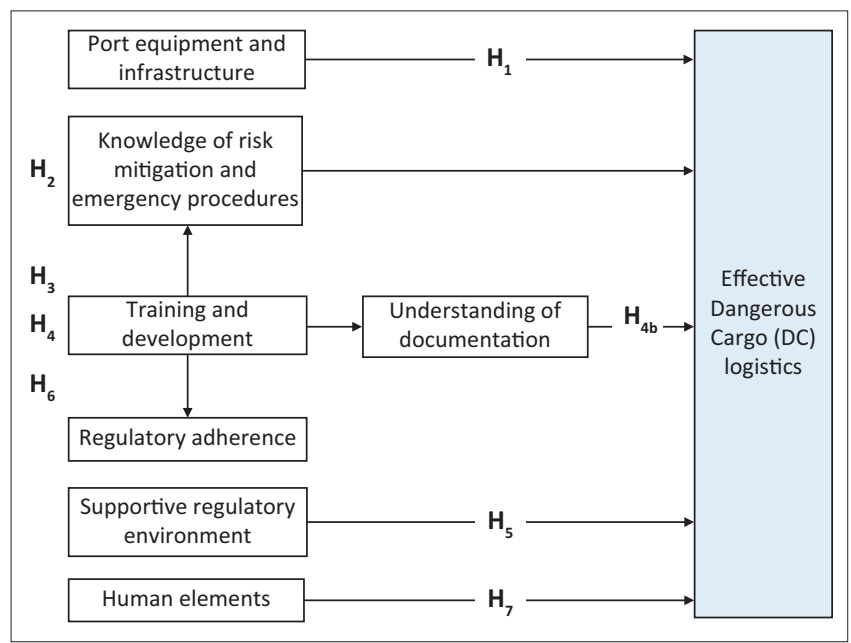

DC, dangerous cargo.

FIGURE 2: Conceptual framework of the study.
These elements were also confirmed by the key informant interviewees.

The results of the study illustrated in Figure 3 confirm the totality of HRC logistics activities as reiterated by McCurry (2014), who postulates that DC logistics starts from the point when the goods are prepared for shipping, and continues through the actual shipping right through to the destination port.

\section{Factors influencing the effectiveness of high-risk cargo logistics at Namibian seaports}

The study regarded effective HRC logistics as an accident-free handling and transportation environment for HRC within the port area (Mokhtar, Shah \& Puan 2016). It emerged from the study that there were those factors that facilitated and those that hindered the effectiveness of HRC logistics activities at Namibian seaports.

\section{Facilitating factors}

Based on their experiences with their respective ports, respondents were asked to indicate their opinions regarding the level of influence of the factors in Table 2 on the effectiveness of HRC logistics. Responses were rated

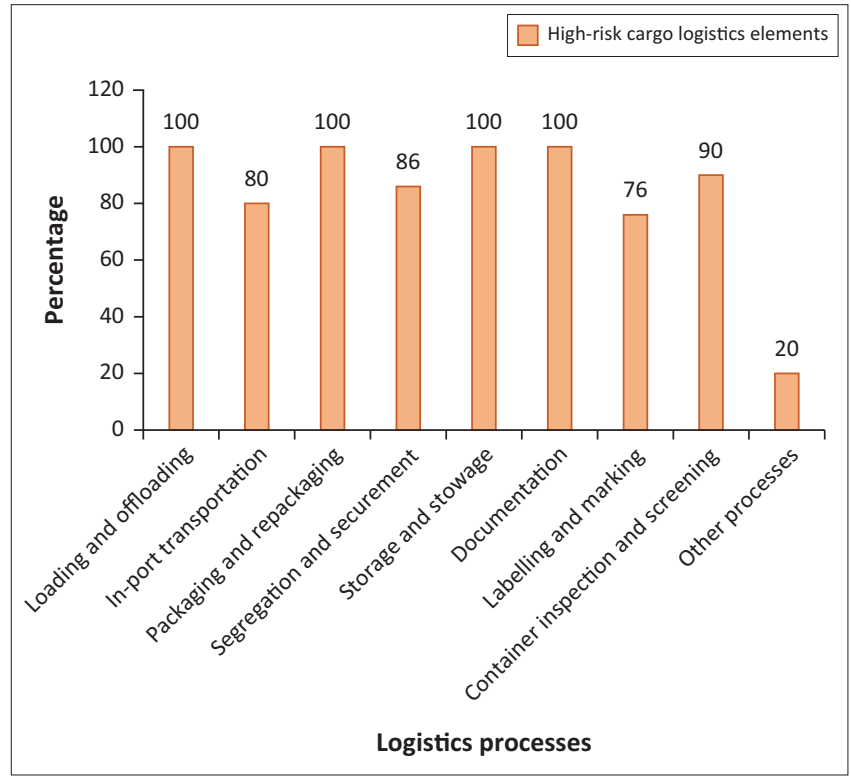

FIGURE 3: Elements of high-risk cargo logistics processes.

TABLE 2: Level of factors influencing the effectiveness of high-risk cargo logistics.

\begin{tabular}{|c|c|c|c|c|c|c|c|c|}
\hline \multirow[t]{2}{*}{ Factors } & \multicolumn{7}{|c|}{ Frequencies ( $\%$ age) } & \multirow[t]{2}{*}{ Totals (\%) } \\
\hline & VL (\%) & L (\%) & $\begin{array}{c}\text { Combined } \\
\text { low influence (\%) }\end{array}$ & NS (\%) & $H(\%)$ & VH (\%) & $\begin{array}{c}\text { Combined } \\
\text { high influence }(\%)\end{array}$ & \\
\hline Appropriate port equipment and infrastructure & 0 & 3 & 3 & 1 & 80 & 16 & 96 & 100 \\
\hline Training and development & 14 & 15 & 29 & 0 & 11 & 60 & 71 & 100 \\
\hline Adequate and correct documentation & 4 & 38 & 42 & 8 & 10 & 40 & 50 & 100 \\
\hline Independence of regulatory framework & 25 & 23 & 48 & 2 & 20 & 28 & 48 & 100 \\
\hline Human elements & 5 & 10 & 15 & 15 & 30 & 40 & 70 & 100 \\
\hline Port technology utilisation & 3 & 3 & 6 & 5 & 78 & 11 & 89 & 100 \\
\hline
\end{tabular}

VL, Very Low; L, Low; NS, Not Sure; H, High; VH, Very High. 
on a five-point Likert scale of Very Low (VL), Low (L), Not Sure (NS), High $(\mathrm{H})$ or Very High $(\mathrm{VH})$. The findings follow.

The results in Table 2 indicate that all of the factors indicated influenced the effective handling of HRC. The use of appropriate port equipment and infrastructure tops the list, with $96 \%$ of the respondents indicating that this factor had high to very high influence on the effectiveness of HRC logistics. Port technology utilisation came second, with $89 \%$ of the respondents indicating that it had a high to very high influence. Other notable factors included training and development (71\%), human elements $(70 \%)$ and strict adherence to national and international regulations (66\%).

The results were also qualitatively confirmed by the key informant interviewees, whose shared views were that an incident-free port could only be ensured through the use of appropriate and up-to-date port equipment and infrastructure, utilisation of the latest port technologies and continuous training programmes, amongst many other factors. One particular interviewee had this to say:

'[Y]ou see, it's quite a straightforward matter. With your latest, appropriate and adequate handling equipment for dangerous goods, all these accidents you hear of will be a thing of the past ... Look at our equipment, how old it is and what good do you think such an old and poorly maintained equipment could do? With the proper personnel who receive the appropriate dangerous goods training and certification, we could handle these dangerous goods with very minimum incidents ...' (Participant 3, Port Manager, male)

The above results all confirmed the view of Darbra and Casal (2004), whose study emphasised the need for appropriate technical equipment and infrastructure, whilst Chang and Thai (2016) and Gusik et al. (2012) emphasised the importance of training and developing personnel responsible for handling HRC. Whilst the determinants of HRC are fragmented in literature, the findings of this study document and put together the determinant factors for future studies.

However, a marginal majority of $50 \%$ of the respondents rated high to very high for adequate and correct documentation, and $48 \%$ for independence of regulatory framework. An average of $46 \%$ of the respondents were of the view that these two factors had low to very low influence of the effectiveness of HRC logistics. This confirms the view by Wang et al. (2015) that a regulatory framework on its own does not warrant effective DC logistics. It is either adherence or violation of the regulations and information on the documents that will have an impact on the effectiveness of the logistics procedures (Frittelli 2008; IMO 2018; Zhang \& Roe 2019).

\section{Factors hindering the effectiveness of high-risk cargo logistics}

Based on their experience with their respective ports, respondents were asked to indicate the level of influence of the factors that were thought to be hindering the effectiveness of HRC logistics, as guided by literature. Table 3 summarises the findings from the study.

Whilst results in Table 1 showed the facilitating factors of effective HRC logistics, the results in Table 3 imply that the lack of, inadequacy or violation of the facilitating factors hinder the effectiveness thereof. For instance, $87 \%$ of the respondents rated poor traffic management as having a high to very high influence, followed by the use of inappropriate equipment and infrastructure (86\%) and poor port technology utilisation (85\%). All of the other factors were also rated as having a relatively high negative influence on the effectiveness of HRC logistics. A marginal majority of $50 \%$, that rated 'inadequate and incorrect documentation' as having a high to very high influence was not surprising, given the controversies that still emerge, even in literature regarding the impact of the adequacy and/or violation of documentation and regulations (Frittelli 2008). Despite this controversy that was confirmed by the study's findings, the rest of the findings confirmed the isolated literature's views regarding the factors impeding the effectiveness of HRC logistics - including the use of inappropriate or inadequate equipment and infrastructure (Loh \& Thai 2015), violation of national and international regulations (Frittelli 2008), lack of training (Cao \& Meng 2017), human errors and failures (Pak et al. 2015), and poor port traffic management (Niavis \& Tsekeris 2012), amongst other impeding factors.

TABLE 3: Level of factors hindering the effectiveness of high-risk cargo logistics.

\begin{tabular}{|c|c|c|c|c|c|c|c|c|}
\hline \multirow[t]{2}{*}{ Factors } & \multicolumn{7}{|c|}{ Frequencies ( $\%$ age) } & \multirow[t]{2}{*}{ Totals } \\
\hline & VL & $\mathbf{L}$ & $\begin{array}{c}\text { Combined low } \\
\text { influence }\end{array}$ & NS & $\mathbf{H}$ & VH & $\begin{array}{c}\text { Combined } \\
\text { high influence }\end{array}$ & \\
\hline Use of inappropriate equipment and infrastructure & 0 & 0 & 0 & 14 & 73 & 13 & 86 & 100 \\
\hline Lack of knowledge of emergency procedures & 15 & 15 & 30 & 0 & 11 & 59 & 70 & 100 \\
\hline Lack of training, retraining and development & 4 & 3 & 7 & 21 & 40 & 32 & 72 & 100 \\
\hline Inadequate and incorrect documentation & 23 & 21 & 44 & 6 & 42 & 8 & 50 & 100 \\
\hline Violation of high-risk cargo international regulations & 5 & 15 & 20 & 8 & 30 & 42 & 72 & 100 \\
\hline Frequent human errors and failures & 13 & 3 & 16 & 25 & 40 & 19 & 59 & 100 \\
\hline Poor port technology utilisation & 4 & 2 & 6 & 9 & 73 & 12 & 85 & 100 \\
\hline Poor port traffic management & 2 & 1 & 3 & 10 & 50 & 37 & 87 & 100 \\
\hline
\end{tabular}

VL, Very Low; L, Low; NS, Not Sure; H, High; VH, Very High. 


\section{Correlation matrix of the study's variables}

A bivariate Pearson Correlation test (two-tailed) was run to test the significance of the relationships between the variables of the study. Table 4 illustrates the correlation matrix for $\mathrm{T}=t-2$ (Listwise $N=78$ ) with the relationships between the study constructs and their loadings. Initially, the results showed high correlations, and it was likely that there could be problems with multicollinearity as inferred by Tamura et al. (2017). A multicollinearity test was thus run and Variance Inflation Factors (VIF) were calculated for each variable. Based on the VIF threshold of 10 (considered high enough to cause multicollinearity problems), highly-correlated variables were to be eliminated to correct the multicollinearity problem as suggested by Tamura et al. (2017). Bruns (2017) notes that if this problem is not eliminated, it may result in inflated standard errors and inconsistent estimates. Variable 5 (operational regulatory environment) was removed and this made theoretical sense, given that regulations on their own do not necessarily influence the effectiveness of DC handling but rather adherence (IMO 2018). Table 4 illustrates the correlation matrix of the study's variables.

Eigen values for the three variables were most significant. Firstly, it was variable 3 (appropriate training and development, Eigen value of 3.849), followed by variable 2 (knowledge of risk mitigation and emergency procedures, Eigen value $=2.871$ ) and lastly, variable 4 (knowledge of DC documentation, Eigen value $=1.320$ ). The Eigen values for these three were greater than 1 and hence they were considered more useful (Tamura et al. 2017). Variable 1 (port equipment and infrastructure) could not, however, be neglected, given that it was closer to 1. Generally, the results confirmed that appropriate training is a predictor of other determinants such as risk mitigation knowledge, regulation adherence and documentation knowledge and interpretation as confirmed by the positive correlations in the Pearson Correlation test results of these determinants.

\section{Summary of hypothesis results}

Eight hypotheses were proposed from the conceptual framework of the study. Proposed hypotheses from the conceptual framework were tested statistically to verify or falsify relationships that were included or excluded in the proposed integrated theory for HRC logistics determinants. A Pearson Chi-Square test of associations was run for each of the proposed hypotheses, whilst Cramer's Value tests were used to evaluate the strength of each relationship. Table 5 illustrates the hypotheses' test results. All hypothesised relationships were significant at $p<0.05$. Hypothesis testing was done in order to determine the significance of the hypothesised relationships (illustrated in Figure 2) and effective DC logistics.

Eight of the projected hypotheses were supported, although one was rejected. The hypotheses' results also confirm the preceding findings from the remote empirical evidence reviewed in literature.

TABLE 4: Correlation matrix. $\dagger$

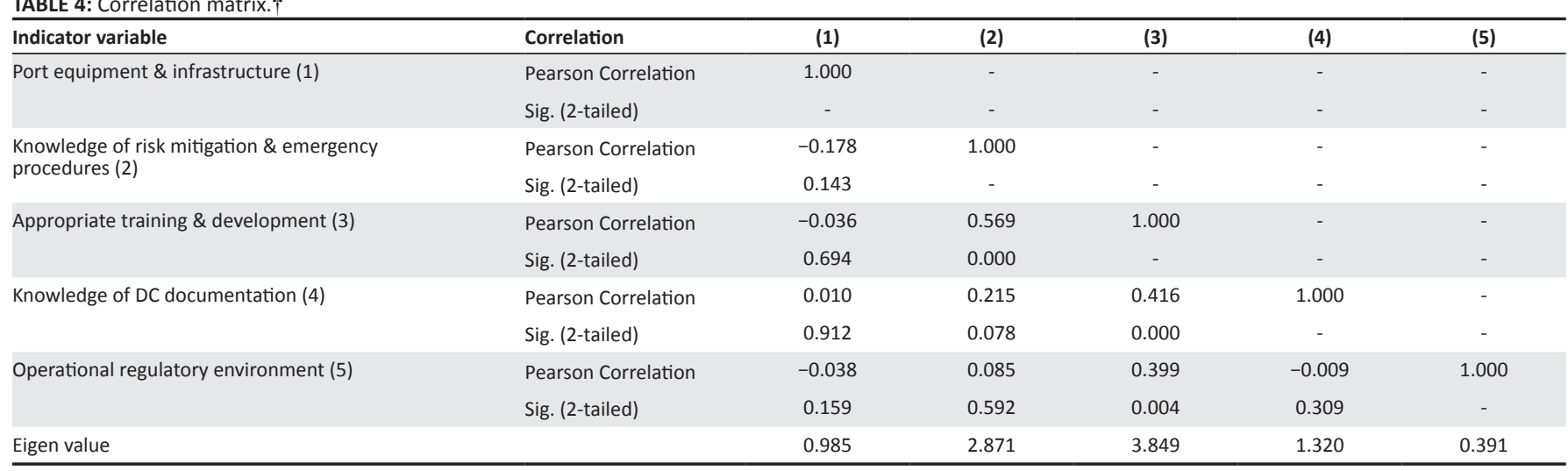

DC, dangerous cargo.

$\dagger$, Listwise $N=78$.

TABLE 5: Hypothesis tests results.

\begin{tabular}{|c|c|c|}
\hline Hypothesis & $p$ & Remarks \\
\hline $\mathrm{H}_{1}$ : Effective DC handling is dependent on appropriate and adequate port equipment and infrastructure & $* * *$ & Supported \\
\hline $\mathrm{H}_{2}$ : Effective DC handling depends on the level of knowledge of risk mitigation and emergency procedures & $* * *$ & Supported \\
\hline $\mathrm{H}_{3}$ : There is a positive association between training and development and the level of knowledge of risk mitigation and emergency procedures & $0.025^{*}$ & Supported \\
\hline $\mathrm{H}_{4 \mathrm{a}}$ : There is a positive association between training and development and the level of understanding and interpretation of HRC documentation & $0.002 * *$ & Supported \\
\hline $\mathrm{H}_{4 \mathrm{~b}}:$ There is a positive association between effective DC handling and the level of understanding of the documentation involved & $* * *$ & Supported \\
\hline $\mathrm{H}_{5}$ : Effective DC handling can be influenced positively by a supportive operational and regulatory environment & 0.784 & Not Supported \\
\hline $\mathrm{H}_{7}$ : There is a positive relationship between human elements and effective $\mathrm{DC}$ handling and the human elements & $0.003 * *$ & Supported \\
\hline
\end{tabular}


The hypothesis that 'Effective DC handling can be influenced positively by a supportive operational and regulatory environment' was rejected. This confirms the notion that regulations on their own do not influence the effectiveness of HRC handling. It is either their enforcement or violation that will determine the effectiveness, as alluded to by Frittelli (2008) and IMO (2018). Similarly, proper documentation on its own will not yield effective HRC logistics - it is the human aspect of proper understanding and interpretation of the documents that will make individuals act in a certain manner.

The study also confirmed the association between training and development and the level of knowledge of risk mitigation and emergency procedures, documentation understanding, and regulations adherence. This implies that how port employees behave in mitigating port risks and in cases of emergency is determined by their level of knowledge of such, which is determined by prior training. Based on the correlation matrix and hypothesis testing results above, the following conceptual framework of the study illustrates the relationships that were verified or confirmed, those that were unconfirmed, and those that emerged. This guided the researchers in proposing a new theory for the determinants of HRC logistics in developing economies (Figure 4).

\section{Summary of interview results}

Validation of the research problem and data on HRC operational insights of the seaports under study could be obtained from interviewing the seaport management and supervisory team who oversaw the handling of HRC. Each interview lasted for about $30 \mathrm{~min}$ and was transcribed and/ or recorded (with consent) for a qualitative analysis and interpretation. Guided by Bengtsson (2016), a content analysis method was used to analyse the transcribed interviews so as to organise and obtain meaning and to draw conclusions. Data obtained were organised into four themes in line with the relevant sub-problems of the study. A summary of key texts extracts from the interview transcripts is presented in Table 6 .

The results confirm most of the quantitative findings as they demonstrate the totality of the elements of HRC handling procedures followed at the seaport and the HRC determinants thereof.

\section{Managerial implications, conclusion and recommendations}

Namport (2015) reported that the cargo that is handled through the Walvis Bay Port is set to increase to about 900000 Twenty Foot Equivalent Units (TEUs) annually once the ongoing expansion is complete. As an envisaged Southern African logistics hub, the issue of safety in DC logistics from both within and without the port remains of concern. The study's findings and results interpretation provided sufficient evidence to suggest that the current HRC logistics safety

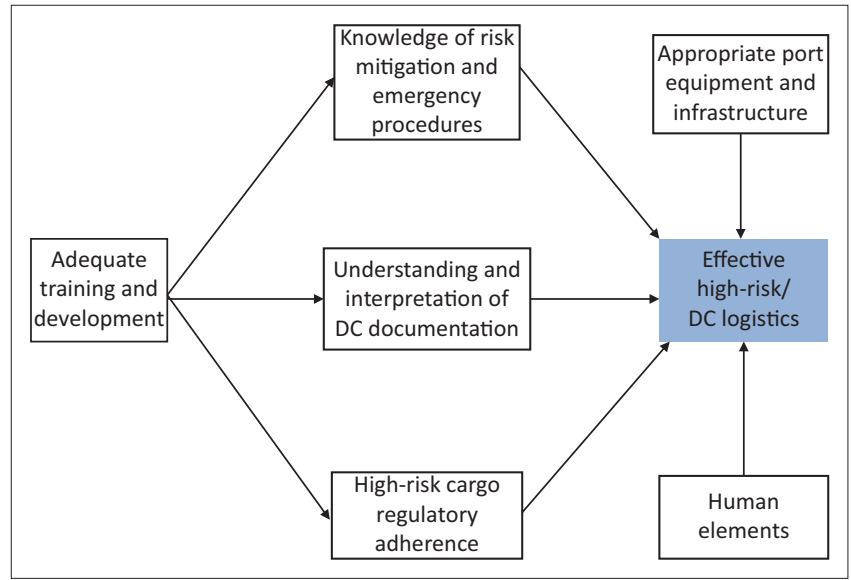

DC, dangerous cargo.

FIGURE 4: Determinants of effective high-risk cargo logistics.

TABLE 6: Summary of key text extracts from the study's interview transcripts.

\section{Themes}

Elements of high-risk cargo handling procedures

Determinants of the effectiveness of handling high-risk cargo (Influences)

Overcoming logistical challenges in handling and controlling high-risk cargo

Logistical challenges in handling and controlling high-risk cargo
Summary of key texts from interviews

Loading and offloading, transportation in and out of the port area

Warehousing, breaking bulk storage, container handling

Packaging and repackaging

Documentation, labelling and marking

Appropriate and adequate handling equipment for dangerous goods Adequately trained and DG-certified personnel

Trained and certified employees must do correct documentation

Employees should know what to do in case of an emergency

Training and buying good equipment

Employee motivation

Acquisition of latest equipment and technologies

Old and poorly-maintained equipment

Lack of appropriately qualified people

Periodic violation of DC rules and regulations by some employees

Lack of appropriate cargo handling equipment

Poor administration of high-risk cargo documents

Under-funding of port equipment maintenance

Invest in appropriate latest equipment and technologies

Train, certify, re-certify and engage in staff retention programmes

On-job training

Sponsor port employees for external training on proper handling of dangerous goods

Educate employees about the negative effects of dangerous goods accidents

Educate employees about the consequences of regulation violations

Buy new equipment

Ensure that dangerous goods are not handled in populated areas of the port

$D C$, dangerous cargo; DG, dangerous goods. 
processes at Namibian seaports can be improved through the use of: adequate and appropriate port equipment and infrastructure; increasing the level of knowledge of risk mitigation and emergency procedures; appropriate training and development; improving the level of understanding the documentation involved in HRC logistics; and improving factors influencing the human elements of all involved in handling HRC at the ports.

The study's findings, however, did not provide sufficient evidence to prove that effective DC handling can be influenced positively merely by a supportive operational regulatory environment, but rather strict adherence to the HRC regulations. The finding that strict adherence to regulation is important implies that port management should take note of the need to enforce rules and regulations adherence.

Based on the confirmed hypotheses of the study and emerging relationships, the study proposes a theoretical framework for the determinants of effective HRC logistics (Figure 4). The study thus contributes an integrated view of the determinants of effective HRC logistics from a collection of isolated literature views. The framework portrays a combination of human and technical determinants. Adequate training and development also emerged as a critical determinant of knowledge of risk mitigation and emergency procedures, the understanding and interpretation of DC documentation and HRC regulatory adherence, which in turn influence the effectiveness of HRC logistics. This finding thus implies that it is imperative that port employees handling HRC should be trained, certified and re-certified to ensure strict adherence to laws, correct interpretation and application of DC documentation, and hence, effective HRC logistics.

Based on the above conclusions, the study emphasises the need for training, retraining and certifying employees, particularly those that handle HRC either directly or indirectly. This will go a long way in alleviating unnecessary port accidents and pollution, hence minimising the negative impacts that come along with such incidents.

It is also important to give general familiarisation training to all of the port employees and the surrounding port communities, on HRC emergency and disaster preparedness. The use of simulations can also help in enhancing the familiarisation programmes.

Human elements emerged as one of the key determinants of effective handling of HRC. Literature also affirmed several human elements to port safety, such as fatigue, miscommunication and instruction misinterpretations, health, work and personal stress (Fabiano et al. 2010; Popek 2019). The finding that human elements are critical to handling HRC at seaports implies that port management should invest in the well-being, safety and protection of the port employees, and generally improve their morale and retention, as this could help in reducing human errors.

The overall findings of the study imply the need for ports to educate employees about the negative effects of DG's accidents as well as the consequences of HRC regulation violations. The extracts from the study's interview transcripts further support the ports' need to ensure that DGs are not handled in populated areas of the port.

\section{Limitations and areas for future research}

The topic presented few prior studies on the determinants of HRC logistics, especially from a developing economy perspective. Although this presented a gap that the study filled, limited prior studies also meant limited access to methodologies that might have been applied in the past. The use of mixed methodologies was thus deemed the most appropriate in exploring the topic

In carrying out the study, it became clear that different classes of HRC may have varying logistical requirements as specified by IMO (2018). Future studies could investigate the specific determinants for the different classes of HRC. Such studies could help in providing specific guidelines relating to the different classes of DC and hence further improve port safety.

\section{Acknowledgement}

The author wishes to thank the anonymous reviewers whose invaluable comments and inputs greatly helped to improve this paper. The author appreciates the feedback obtained through the 2018 IBC (Mauritius) and 2020 AIB-Africa and AIB-US NE Special Joint (Kenya) Conferences that helped improve the earlier versions of the paper.

\section{Competing interest}

The author has declared that no competing interests exist.

\section{Authors contributions}

I declare that I am the sole author of this research article.

\section{Funding informations}

This research received no specific grant from any funding agency in the public, commercial or not-for-profit sectors.

\section{Data availability statement}

Data sharing is not applicable to this article as no new data were created or analysed in this study.

\section{Disclaimer}

The views and opinions expressed in this article are those of the authors and do not necessarily reflect the official policy or position of any affiliated agency of the authors. 


\section{References}

Ajzen, I., 1991, 'The theory of planned behaviour', Organizational Behaviour and Human Decision Processes 50(2), 179-211. https://doi.org/10.1016/0749 5978(91)90020-T

Alderton, P. \& Saieva, G., 2013, Port management and operations, Taylor \& Francis, London.

Attia, M. \& Edge, J., 2017, 'Be(com)ing a reflexive researcher: A developmental approach to research methodology', Open Review of Educational Research 4(1), 33-45. https://doi.org/10.1080/23265507.2017.1300068

Batarlienè, N., 2018 December, 'Dangerous goods transport problems in Lithuania', in Varhelyi, A., Žuraulis, V. \& Prentkovskis, O. (Eds.) Conference vision zero for sustainable road safety in Baltic sea region, pp. 67-73, Springer, Cham.

Bengtsson, M., 2016, 'How to plan and perform a qualitative study using conten analysis', NursingPlus Open 2, 8-14. https://doi.org/10.1016/j.npls.2016.01.001

Berke, P.R., Kartez, J. \& Wenger, D., 1993, 'Recovery after disaster: Achieving sustainable development, mitigation and equity', Disasters 17(2), 93-109. https:// doi.org/10.1111/j.1467-7717.1993.tb01137.x

Brannen, J., 2005, 'Mixing methods: The entry of qualitative and quantitative approaches into the research process', International Journal of Social Research Methodology 8(3), 173-184. https://doi.org/10.1080/13645570500154642

Bruns, S.B., 2017, 'Meta-regression models and observational research', Oxford Bulletin of Economics and Statistics 79(5), 637-653. https://doi.org/10.1111/ obes.12172

Callaghan, C.W., 2016, 'Disaster management, crowdsourced R\&D and probabilistic innovation theory: Toward real time disaster response capability', Internationa Journal of Disaster Risk Reduction 17, 238-250. https://doi.org/10.1016/j. ijdrr.2016.05.004

Cao, X. \& Meng, Q., 2017, 'Dockworkers' resistance and union reform within China's globalised seaport industry', Globalizations 14(2), 272-284. https://doi.org/10.10 80/14747731.2016.1203131

Chang, C.H. \& Thai, V.V., 2016, 'Do port security quality and service quality influence customer satisfaction and loyalty?', Maritime Policy \& Management 43(6), 720736. https://doi.org/10.1080/03088839.2016.1151086

Chang, S.E. \& Rose, A.Z., 2012, 'Towards a theory of economic recovery from disasters', International Journal of Mass Emergencies and Disasters 32(2), 171-181.

Cypress, B.S., 2017, 'Rigor or reliability and validity in qualitative research: Perspectives, strategies, reconceptualization, and recommendations', Dimensions
of Critical Care Nursing 36(4), 253-263. https://doi.org/10.1097/DCC.0000000 000000253

Darbra, R.M. \& Casal, J., 2004, 'Historical analysis of accidents in seaports', Safety Science 42(2), 85-98. https://doi.org/10.1016/S0925-7535(03)00002-X

De Klerk, E., 2013, Southern Africa: Namport Fast-Tracks N\$30-Billion SADC Gateway, viewed 11 February 2019, from https://allafrica.com/stories/201307100923. html.

De Klerk, E., 2018, Government investigates oil spill on Walvis Bay shores, viewed 12 March 2019, from https://www.newera.com.na/2018/03/12/govt-investigatesoil-spill-on-walvis-bay-shores/.

Ding, D. \& Chou, M.C., 2015, 'Stowage planning for container ships: A heuristic algorithm to reduce the number of shifts', European Journal of Operational Research 246(1), 242-249. https://doi.org/10.1016/j.ejor.2015.03.044

Ellis, J., 2011, 'Analysis of accidents and incidents occurring during transport of packaged dangerous goods by sea', Safety Science 49(8-9), 1231-1237. https:// doi.org/10.1016/j.ssci.2011.04.004

Fabiano, B., Curro, F., Reverberi, A.P. \& Pastorino, R., 2010, 'Port safety and the container revolution: A statistical study on human factor and occupational accidents over the long period', Safety Science 48(8), 980-990. https://doi. org/10.1016/j.ssci.2009.08.007

Finck, O., 2017, Namport looking to increase Botswana import volumes, viewed 11 March 2019, from https://www.erongo.com.na/infrastructure/namport-lookingincrease-botswana-import-volumes.219978.

Frémont, A., 2008, 'Empirical evidence for integration and disintegration of maritime shipping, port and logistics activities (No. 2009-1)', Discussion paper, OECD/ITF Joint Transport Research Centre (JTRC), Paris. https://doi. org $/ 10.1787 / 227565346707$

Frittelli, J., 2008, 'Port and maritime security: Background and issues for congress', Port and Maritime Security 11, 1-27. https://doi.org/10.1080/07266472.2008.10 878889

Gusik, V., Klumpp, M. \& Westphal, C., 2012, International comparison of dangerous goods transport and training schemes, Essen, FOM, Germany.

He, G., Zhang, L., Lu, Y. \& Mol, A.P., 2011, 'Managing major chemical accidents in China: Towards effective risk information', Journal of Hazardous Materials 187(1) 171-181.

House, D.J., 2015, Cargo work: For maritime operations, Routledge, London.

International Labour Organisation (ILO), 2018, Port worker development programme, viewed 02 June 2018, from https://www.ilo.org/sector/Resources/trainingmaterials/WCMS_161227/lang--en/index.htm.

International Maritime Organisation (IMO), 2018, International maritime dangerous goods (IMDG) code, 2016 edn., viewed 02 December 2018, from https://www. imo.org/en/Publications/Documents/IMDG\%20Code/IMDG\%20Code\%20 2016\%20Edition/QK200E_122017.pdf.
John, A., Paraskevadakis, D., Bury, A., Yang, Z., Riahi, R. \& Wang, J., 2014, 'An integrated fuzzy risk assessment for seaport operations', Safety Science 68, 180-194. https:// doi.org/10.1016/j.ssci.2014.04.001

Koehler, G.A., Kress, G.G. \& Miller, R.L., 2014, 'What disaster response management can learn from chaos theory', Crisis and Emergency Management: Theory and Practice 178, 111. https://doi.org/10.1201/b16715-11

Kulshreshtha, A.C., 2013, Basic concepts of sampling: Brief review, sampling frame viewed 18 May 2018, from https://www.unsiap.or.jp/e-learning/el_material/ Agri/rap2/ag_02_03_L1_BasicConcepts_Sampling_Frame.pdf.

Kunz, N., Reiner, G. \& Gold, S., 2014, 'Investing in disaster management capabilities versus pre-positioning inventory: A new approach to disaster preparedness', International Journal of Production Economics 157, 261-272. https://doi. org/10.1016/j.ijpe.2013.11.002

Lam, J.S.L. \& Lassa, J.A., 2017, 'Risk assessment framework for exposure of cargo and ports to natural hazards and climate extremes', Maritime Policy \& Management 44(1), 1-15. https://doi.org/10.1080/03088839.2016.1245877

Liu, J., Zhou, H. \& Sun, H., 2019, 'A three-dimensional risk management model of port logistics for hazardous goods', Maritime Policy \& Management 46(6), 1-20. https://doi.org/10.1080/03088839.2019.1627435

Loh, H.S. \& Thai, V.V., 2015, 'Management of disruptions by seaports: Preliminary findings', Asia Pacific Journal of Marketing and Logistics 27(1), 146-162. https:// doi.org/10.1108/APJML-04-2014-0053

Mah, A., 2015, 'Dangerous cargo and uneven toxic risks: Petrochemicals in the port of New Orleans', in Birtchnell, T., Savitzky, S., \& Urry, J. (Eds.). (2015). Cargomobilities: moving materials in a global age, pp. 149-162, Routledge, New York and London.

Mangan, J., Lalwani, C. \& Fynes, B., 2008, 'Port-centric logistics', The International Journal of Logistics Management 19(1), 29-41. https://doi.org/10.1108/09574 090810872587

Martins, M.R., Pestana, M.A., Souza, G.F.M. \& Schleder, A.M., 2016, 'Quantitative risk analysis of loading and offloading liquefied natural gas (LNG) on a floating storage and regasification unit (FSRU)', Journal of Loss Prevention in the Process Industries 43, 629-653. https://doi.org/10.1016/j.jlp.2016.08.001

McCurry, J., 2014, Dangerous goods safe shipping requires cooperation throughout supply chain, viewed 12 March 2019, from https://aircargoworld.com/allposts/ dangerous-goods-safe-shipping-requires-cooperation-throughout-supplydangerous-g
chain-10003/.

Min, H., 2012, 'Maritime logistics and supply chain security', in Song, D.-W. and Panayides, P.M. (Ed.) Maritime logistics: Contemporary issues, (pp. 91-116) Emerald Group Publishing Limited, Bingley, United Kingdom.

Mokhtar, K., Shah, M.Z. \& Puan, O.C., 2016, 'Risk management and supply chain: A conceptual theory in seaport', Journal Pengurusan 48(16), 1-11.

Molero, G.D., Santarremigia, F.E., Aragonés-Beltrán, P. \& Pastor-Ferrando, J.P., 2017, 'Total safety by design: Increased safety and operability of supply chain of inland terminals for containers with dangerous goods', Safety Science 100, 168-182. https://doi.org/10.1016/j.ssci.2016.10.007

Montwiłł, A., 2014, 'The role of seaports as logistics centres in the modelling of the sustainable system for distribution of goods in urban areas', Procedia-Social and Behavioural Sciences 151, 257-265. https://doi.org/10.1016/j.sbspro.2014. 10.024

Mullai, A., 2006, Maritime transport and risks of packaged dangerous goods, DaGoB publication series, Turku.

Namibia Ports Authority (Namport), 2015, Annual report 2014/2015, Walvis Bay, Namport.

Namport, 2018, 2016-2017 Namport annual report, viewed 07 June 2019, from https://www.namport.com.na/files/documents/003 Stats\%202016 2017.pdf.

Namport, 2019a, Botswana Dry Port expands its services at Port of Walvis Bay, viewed 14 April 2020, from https://www.namport.com.na/news/532/botswana-dryport-expands-its-services-at-port-of-walvis-bay/.

Namport, 2019b, Namport Mega projects, viewed 14 April 2020, from https://www. namport.com.na/mega-projects/new-container-terminal/371/.

Niavis, S. \& Tsekeris, T., 2012, 'Ranking and causes of inefficiency of container seaports in South-Eastern Europe', European Transport Research Review 4(4), 235-244. https://doi.org/10.1007/s12544-012-0080-y

Ots, T., 2000, Transport and handling of dangerous cargoes in port areas: Weaknesses of existing international and Estonian regulations, viewed 03 March 2019, from https:// commons.wmu.se/cgi/viewcontent.cgi?article=1242\&context=all_dissertations.

Pak, J.Y., Yeo, G.T., Oh, S.W. \& Yang, Z., 2015, 'Port safety evaluation from a captain's perspective: The Korean experience', Safety Science 72, 172-181. https://doi. org/10.1016/j.ssci.2014.09.007

Pearce, L., 2003, 'Disaster management and community planning, and public participation: How to achieve sustainable hazard mitigation', Natural Hazards 28(2-3), 211-228.

Pinto, R., 2010, 'Mixed methods design', in N.J. Salkind (ed.), Encyclopaedia of research design: Mixed methods design, pp. 813-819, Sage Publications, Thousand Oaks, CA.

Popek, M., 2019, Factors influencing on the environment during hazardous goods transportation by the se, viewed 03 March 2019, from https://iopscience.iop.org/ article/10.1088/1755-1315/214/1/012052/pdf

Probst, B., 2015, 'The eye regards itself: Benefits and challenges of reflexivity in qualitative social work research', Social Work Research 39(1), 37-48. https://doi. org/10.1093/swr/svu028 
Rodrigue, J.P., Comtois, C. \& Slack, B., 2016, The geography of transport systems, Routledge, London.

Rothblum, A.M., 2004, Human error and marine safety, U.S. Coast Guard Research \& Development Centre, New London.

Rubin, C., 1991, 'Recovery from disaster', in T.E. Drabek \& G.J. Hoetmer (eds.), Emergency management: Principles and practice for local government pp. 224-261, International City, Washington, DC.

Santis, S.H.D.S.D. \& Marcicano, J.P.P., 2020, 'Criteria for carriage of dangerous cargo class 1-explosives in Brazil', International Journal of Logistics Systems and class 1-explosives in Brazil', International Journal of Logistics Systems
Management 35(4), 425-435. https://doi.org/10.1504/IJLSM.2020.106249

Saruchera, F., 2017, 'Rail freight transportation concerns of developing economies: A Namibian perspective', Journal of Transport and Supply Chain Management 11(1) 1-9. https://doi.org/10.4102/jtscm.v11i0.288

Savage, C.J., Fransman, L., Jenkins, A.K. \& Bamford, C.G., 2014, 'Developing Walvis Bay port into a logistics gateway for Southern Africa: Issues, challenges and the potential implications for Namibia's future', Journal of Transport and Supply Chain Management 8(1), 1-10. https://doi.org/10.4102/jtscm.v8i1.154

Smith, G., Martin, A. \& Wenger, D.E., 2018, 'Disaster recovery in an era of climate change: The unrealized promise of institutional resilience', in H. Rodríguez, E.L. Quarantelli, \& R.R. Dynes (Eds.) Handbook of disaster research, pp. 595-619, Springer, New York, NY.

Sukmanee, J., Kesvarakul, R. \& Janthong, N., 2019, 'A methodology of network modelling of risk prioritization in hazardous product transportation', in M.Y. Wang (ed.) 2019 IEEE international conference on industrial engineering and engineering management (IEEM), pp. 955-959, IEEE, Macau.

Takhar, A. \& Chitakunye, P., 2012, 'Rich descriptions: Evoking informant self-reflexivity in marketing and consumer research', Journal of Marketing Management 28(7), 912-935. https://doi.org/10.1080/0267257X.2012.700316

Tamura, R., Kobayashi, K., Takano, Y., Miyashiro, R., Nakata, K. \& Matsui, T., 2017, 'Best subset selection for eliminating multicollinearity', Journal of the Operation Research Society of Japan 60(3), 321-336. https://doi.org/10.15807/jorsj.60.321

Tanackov, I., Janković, Z., Sremac, S., Miličić, M., Vasiljević, M., Mihaljev-Martinov, J. et al., 2018, 'Risk distribution of dangerous goods in logistics subsystems', Journal of Loss Prevention in the Process Industries 54, 373-383. https://doi.org/10.1016/j. jlp.2018.03.013

Thai, V.V., 2016, 'Competencies required by port personnel in the new era: Conceptua framework and case study', International Journal of Shipping and Transport Logistics 4(1), 49-77. https://doi.org/10.1504/IJSTL.2012.044135
Tsinker, G., 2014, Handbook of port and harbour engineering: Geotechnical and structural aspects, Springer, New York, NY.

United Nations (UN), 2011, Committee of experts on the transport of dangerous goods recommendations on the transport of dangerous goods: Model regulations, vol. 1, United Nations Publications, New York, NY.

Wallace, M. \& Webber, L., 2017, The disaster recovery handbook: A step-by-step plan to ensure business continuity and protect vital operations, facilities, and assets, AMACOM, New York, NY

Wang, C.H., Wu, M.E. \& Chen, C.M., 2015, 'Inspection risk and delay for screening cargo containers at security checkpoints', in P. Jeng-Shyang, L. Ivan, H. HsiangCheh and Y. Ching-Yu (eds.) Intelligent information hiding and multimedia signa processing (IIH-MSP), 2015 international conference, pp. 211-214, IEEE, Adelaide, Australia.

Weichselgartner, J., 2001, 'Disaster mitigation: The concept of vulnerability revisited', Disaster Prevention and Management: An International Journal 10(2), 85-95. https://doi.org/10.1108/09653560110388609

Wilson, I.D., Roach, P.A. \& Ware, J.A., 2001, 'Container stowage pre-planning: Using search to generate solutions, a case study', Knowledge-Based Systems 14(3-4), 137-145. https://doi.org/10.1016/S0950-7051(01)00090-9

Yang, Y.C., 2011, 'Risk management of Taiwan's maritime supply chain security', Safety Science 49(3), 382-393. https://doi.org/10.1016/j.ssci.2010.09.019

Yang, Y.L., Ding, J.F., Chiu, C.C., Shyu, W.H., Tseng, W.J. \& Chou, M.T., 2016, 'Core risk factors influencing safe handling operations for container terminals at Kaohsiung port', Proceedings of the Institution of Mechanical Engineers, Part M: Journal of Engineering for the Maritime Environment 230(2), 444-453. https://doi. org/10.1177/1475090214563859

Yin, R.K., 2017, Case study research and applications: Design and methods, Sage publications, New Delhi.

Yuen, K.F. \& Thai, V., 2017, 'Barriers to supply chain integration in the maritime logistics industry', Maritime Economics \& Logistics 19(3), 551-572. https://doi. org $/ 10.1057 / \mathrm{mel} .2016 .10$

Zekos, G.I., 2000, 'Safety at sea and air transport under EU law', Managerial Law 42(3), 1-19. https://doi.org/10.1108/03090550010770193

Zhang, X. \& Roe, M., 2019, Maritime container port security, Palgrave Macmillan, Cham, London. 